\title{
Aortopathy and coronary anomaly in bicuspid aortic valve: an uncommon tricky association
}

\author{
Antonio Salsano ${ }^{1,2}$, Roberto Natali ${ }^{1,2}$, Giulia Parolari ${ }^{1,2}$, Davide Ricci ${ }^{1,2}$, Francesco Santini ${ }^{1,2}$ \\ 'Division of Cardiac Surgery, Ospedale Policlinico San Martino, Genoa 16132, Italy. \\ ${ }^{2}$ Department of Surgical and Integrated Diagnostic Sciences (DISC), University of Genoa, Genoa 16132, Italy.
}

Correspondence to: Dr. Antonio Salsano, Division of Cardiac Surgery, Ospedale Policlinico San Martino, L.go Rosanna Benzi 10, Genoa 16132, Italy; Department of Surgical and Integrated Diagnostic Sciences (DISC), University of Genoa, L.go Rosanna Benzi 10, Genoa 16132, Italy. E-mail: ant.salsano@gmail.com

How to cite this article: Salsano A, Natali R, Parolari G, Ricci D, Santini F. Aortopathy and coronary anomaly in bicuspid aortic valve: an uncommon tricky association. Vesse/ Plus 2020;4:21. http://dx.doi.org/10.20517/2574-1209.2020.12

\author{
Received: 26 Apr 2020 First Decision: 26 Apr 2020 Revised: 5 Jun 2020 Accepted: 16 Jun 2020 Published: 19 Jul 2020 \\ Academic Editor: Narasimham L. Parinandi, Antonio Nenna Copy Editor: Cai-Hong Wang Production Editor: Jing Yu
}

\begin{abstract}
Bicuspid aortic valves (BAV) can be associated with aortopathy and coronary anomalies. We report the case of a 60 year-old woman undergoing surgery for severe aortic stenosis due to BAV and an ascending aortic aneurysm. During the procedure, an uncommon anomalous origin of the left main coronary artery from the posterior commissure with intramural takeoff of the left coronary artery was found. Routine pre-operative coronary angiography had failed to identify this anomaly. To avoid ischemic events or left main coronary lesions, we placed the aortic bioprosthesis by respecting the commissures, not to occlude the anomalous coronary ostium. The association of BAV, aortopathy and coronary anomalies is a rare finding. Awareness of the anatomy of the coronary arteries in patients with BAV should be considered mandatory to avoid catastrophic consequences and to select the appropriate surgical procedure.
\end{abstract}

Keywords: Aortic surgery, aortic valve, bicuspid aortic valve, coronary anomaly

\section{INTRODUCTION}

Bicuspid aortic valves (BAV) are the most common congenital heart defect, affecting $1 \%$ to $2 \%$ of the general population $^{[1]}$, and are often associated with aortic aneurysms and occasionally, with coronary anomalies. 


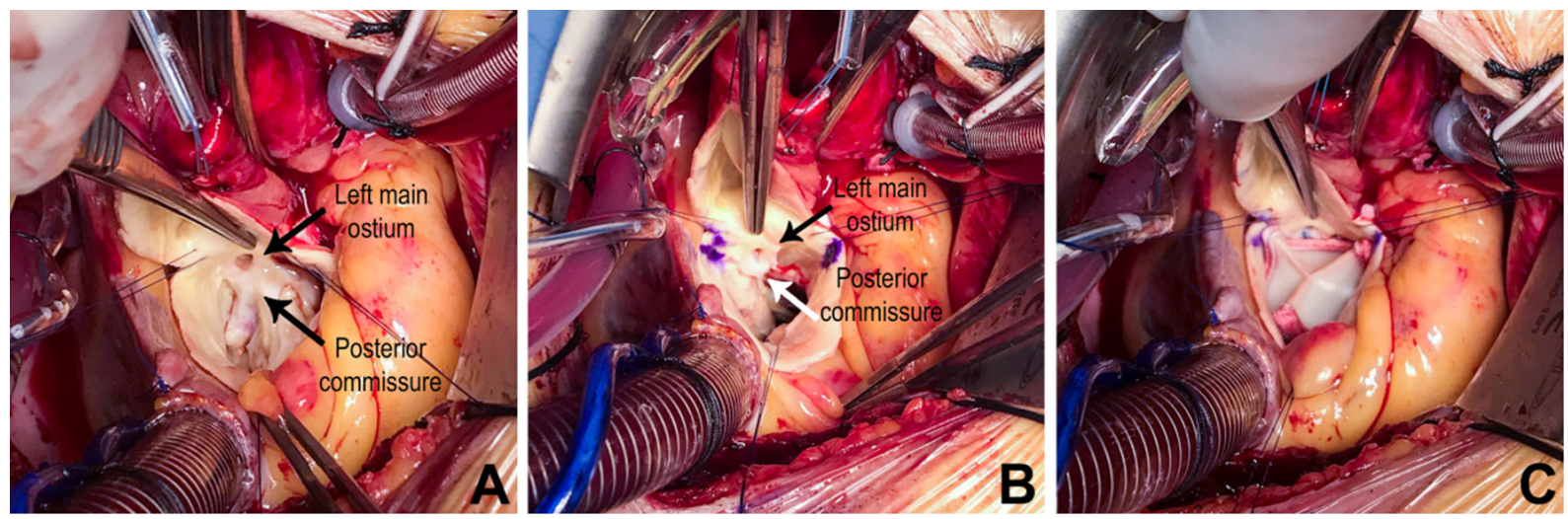

Figure 1. Surgical view of the aortic valve and the left main ostium during the procedure. A: native valve in situ, left main ostium located in proximity to the posterior commissure; B: marked stent location after native valve removal; C: implanted bioprostethic valve; the valve stents are not in conflict with the left main ostium, which has been left in its original location

Various classifications have been introduced to describe the different morphologies of BAVs. One of the most used in clinical practice is the Sievers classification. Introduced in 2007, it is based on the number of raphes to define the phenotype of the BAV, and includes three classes: types 0 (no raphe), 1 (one raphe) and 2 (two raphes); type 0 valves are divided into anteroposterior (AP) or lateral according to spatial position and orientation between the cusps and the coronary ostia ${ }^{[2]}$.

BAV s can develop stenosis or regurgitation and be associated with vascular anomalies. Some studies claim that ascending aortic dilatation is the most common vascular anomaly found in patients with BAVs ${ }^{[3]}$. Various mechanisms are involved including cystic medial necrosis, fragmentation of elastic fibers or the loss of smooth muscle cells in the ascending aorta wall ${ }^{[4]}$. The association between BAV and coronary anomalies has been described as a rare finding in the current literature ${ }^{[5-7]}$. We report a case of BAV stenosis associated with an ascending aortic aneurysm and a positional anomaly of the left main coronary ostium.

\section{CASE REPORT}

A 60-year-old woman presented with acute respiratory distress and chest pain to the emergency room. Her main cardiovascular risk factors included smoking, recurrent bronchitis, hypercholesterolemia, $\beta$-thalassemia trait and a family history of coronary artery disease.

On admission, trans-thoracic echocardiography revealed a dilated ascending aorta $(45 \mathrm{~mm})$ with a normal aortic root, severe aortic valve stenosis (mean gradient $83 \mathrm{mmHg}$ ) in the presence of bicuspid aortic valves, and a regular left ventricular ejection fraction (50\%). Coronary angiography revealed apparently normal coronary anatomy without any critical lesion [Video 1]. Chest x-ray, EKG and Doppler examination of the supra-aortic vessels did not elucidate any anomaly. The patient was therefore transferred to our Division for surgical treatment. We planned for replacement of the aortic valve and ascending aorta through a ministernotomy approach, according to current guidelines ${ }^{[8,9]}$.

In the operating room, a Sievers type 0 AP BAV was recognized. The left main coronary ostium was found to originate in proximity to the posterior commissure, having an intramural take-off and, it was surrounded by thick fibrous tissue, possibly due to acquired jet lesions [Figure $1 \mathrm{~A}$ ]. Interestingly, this anomaly was not detected during the previous routine angiography [Video 1].

Once the native leaflets had been removed and the annulus decalcified, we chose to implant a bioprosthetic valve (Carpentier Edwards Magna Ease size 21), respecting the patient's wishes. 
We marked the location of the bioprosthetic valve stent to avoid the left main lesion and/or mechanical obstruction [Figure 1B]. The fibrous tissue around the ostium was deliberately left intact to avoid inadvertent dissection [Figure $1 \mathrm{~B}$ and $\mathrm{C}$ ]. After valve implantation, the ascending aorta was replaced with a $26 \mathrm{~mm}$-Dacron Hemashield tube graft (Meadox Medicals, Inc., Oakland, New Jersey, N.J. USA). $2 \mathrm{D}$-echocardiography showed good valve function postoperatively with no leak. The postoperative clinical course was uneventful otherwise and no ischemic events occurred. At 6-month follow-up, the patient is alive, asymptomatic and NYHA class I.

\section{DISCUSSION}

Our case included aortopathy and coronary anomaly in a patient with BAV. Coronary anomalies are rare and are found in less than $1 \%$ of the general population ${ }^{[10]}$. Their association with BAVs has been reported, but there is a lack of focused studies in the literature to draw conclusions on detecting these anomalies and the related operative risks ${ }^{[1]}$. Interestingly, routine coronary angiography failed to detect the left main coronary ostium origin anomaly. This is not completely unexpected since a high incidence of false negatives has been reported when the anomaly involves the coronary origin ${ }^{[12]}$. The location, orientation, height and number of coronary ostia may necessitate different surgical approaches, not only during valve replacement surgery, but during valve repair and valve sparing surgery too ${ }^{[13]}$. During aortic valve replacement, it is crucial to rotate the prosthesis so that the stent does not interfere with the anomalous coronary ostia. The surgeon must be careful not to damage the coronary origin to avoid potentially catastrophic ischemic events. In cases of intramural take off of the left coronary artery, as seen in our patient, the aortic root must be manipulated with caution. If rotating the prosthesis is not sufficient to avoid the risk of ischemia, other treatment options include unroofing the intramural segment, creation of a "neo-ostium" in the appropriate sinus, reimplantation of the ostium, translocation of the pulmonary artery, and pericardial patching of the aorta and proximal anomalous coronary artery ${ }^{[14,15]}$. Occasionally, coronary artery bypass grafting is used but it is generally not recommended ${ }^{[14]}$. We must be aware of coronary anomalies even during aortic root surgery. Valve sparing surgery is feasible, although it may be necessary to associate it with corrective surgery of the coronary anomaly. A careful surgical plan is mandatory for successful coronary reimplantation and to avoid air embolism ${ }^{[16]}$.

Despite being used off label with BAV, there are increasing numbers of Transcatheter Aortic Valve Replacement procedures in the last few years ${ }^{[9]}$. In view of the asymmetric nature of the BAV orifice and heavy regional calcification, the risk of ischemia related to coronary anomalies during transcatheter procedures is not negligible ${ }^{[17]}$.

Unfortunately, there is a gap in knowledge such that we are not currently able to identify patients with coronary anomalies and a high risk of ischemia, and to properly stratify the related surgical risk to the correction of coronary anomalies ${ }^{[15]}$.

Considering the potential issues, an accurate pre-operative diagnosis is crucial to avoid adverse outcomes. Since routine angiography cannot be conclusive, as seen in our case, the use of gated coronary-CT, 3D echocardiography or magnetic resonance imaging may be considered ${ }^{[18]}$.

In conclusion, coronary anomalies may be associated with BAVs with potential implications for invasive valve procedures. If underestimated or not recognized, coronary anomalies can lead to catastrophic outcomes.

\section{DECLARATIONS}

\section{Authors' contributions}

Made substantial contribution to the conception and design of the study, performed data analysis and data interpretation: Salsano A, Ricci D, Santini F 
Performed data acquisition, as well as provided administrative, technical, and material support: Salsano A, Natali R, Parolari G

\section{Availability of data and materials}

Not applicable.

\section{Financial support and sponsorship}

None.

\section{Conflicts of interest}

All authors declared that there are no conflicts of interest.

\section{Ethical approval and consent to participate}

Not applicable.

\section{Consent for publication}

The individual details used in this manuscript were obtained with the patient's consent for publication.

\section{Copyright}

(c) The Author(s) 2020.

\section{REFERENCES}

1. Augoustides JG, Wolfe Y, Walsh EK, Szeto WY. Recent advances in aortic valve disease: Highlights from a bicuspid valve to transcatheter aortic valve replacement. J Cardiothorac Vasc Anesth 2009;23:569-75.

2. Sievers HH, Schmidtke C. A classification system for the bicuspid aortic valve from 304 surgical specimens. J Thorac Cardiovasc Surg 2007;133:1228-33.

3. Cecconi M, Nistri S, Quarti A, Manfrin M, Colonna PL, et al. Aortic dilatation in patients with bicuspid aortic valve. J Cardiovase Med (Hagerstown) 2006;7:11-20.

4. Bauer M, Pasic M, Meyer R, Goetze N, Bauer U, et al. Morphometric analysis of aortic media in patients with bicuspid and tricuspid aortic valve. Ann Thorac Surg 2002;74:58-62.

5. Michalowska I M, Hryniewiecki T, Kwiatek P, Stoklosa P, Swoboda-Rydz U, et al. Coronary artery variants and anomalies in patients with bicuspid aortic valve J Thorac Imaging 2016;31:156-62.

6. Loukas M, Patel S, Cesmebasi A, Muresian H, Tubbs RS, et al. The clinical anatomy of the conal artery. Clin Anat 2016;29:371-9.

7. Koenraadt WMC, Bartelings MM, Bokencamp R, Gittenberger-de-Groot AC, DeRuiter MC, et al. Coronary anatomy in children with bicuspid aortic valves and associated congenital heart. Heart 2018;104:385-93.

8. Erbel R, Aboyans V, Boileau C, Bossone E, Di Bartolomeo R, et al. 2014 ESC Guidelines on the diagnosis and treatment of aortic diseases: document covering acute and chronic aortic diseases of the thoracic and abdominal aorta of the adult. The Task Force for the Diagnosis and Treatment of Aortic Diseases of the European Society of Cardiology (ESC). Eur Heart J 2014;35:2873-926.

9. Baumgartner H, Falk V, Bax JJ, De Bonis M, Hamm C, et al. 2017 ESC/EACTS Guidelines for the management of valvular heart disease. Eur Heart J 2017;38:2739-91.

10. DeFaria Yeh D. Coronary artery variants and bicuspid aortic valve disease: gaining insight into genetic underpinnings. Heart 2018;104:363-4.

11. Naito S, Petersen J, Reichenspurner H, Girdauskas E. The impact of coronary anomalies on the outcome in aortic valve surgery: comparison of bicuspid aortic valve versus tricuspid aortic valve morphotype. Interact Cardiovasc Thorac Surg 2018;26:617-22.

12. Lee HJ, Kim YJ, Hur J, Nam JE, Kim TH, et al. Coronary artery anomalies: detection on coronary artery calcium scoring scan. AJR Am J Roentgenol 201;194:W382-7.

13. Sultan I, Konic CM, Bavaria JE. How I teach a valve-sparing root replacement. Ann Thorac Surg 2016;101:422-5.

14. Ong CS, Cameron DE, Jacobs ML. Surgical management of anomalous coronary arteries. Ann Cardiothorac Surg 2018;7:604-10.

15. Brothers JA, Frommelt MA, Jaquiss RDB, Myerburg RJ, Fraser CD Jr, et al. Expert consensus guidelines: anomalous aortic origin of a coronary artery. J Thorac Cardiovasc Surg 2017;153:1440-57.

16. O’Blenes SB, Feindel CM. Aortic root replacement with anomalous origin of the coronary arteries. Ann Thorac Surg 2002;73:647-9.

17. Bertin M, Aboukofa M, Laterre PF, Yousif Z. Case report: TAVI in a patient with single coronary artery and bicuspid valve. Case Rep Cardiol 2020;2020:2569506.

18. Patel PA, Gutsche JT, Vernick WJ, Giri JS, Ghadimi K, et al. The functional aortic annulus in the 3D era: focus on transcatheter aortic valve replacement for the perioperative echocardiographer. J Cardiothorac Vasc Anesth 2015;29:240-5. 